DOI: http://dx.doi.org/10.33846/hn41106

http://heanoti.com/index.php/hn

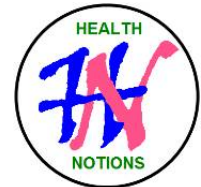

RESEARCH ARTICLE

URL of this article: http://heanoti.com/index.php/hn/article/view/hn41106

\title{
Differences Effectiveness of Percutaneous Nephrolithotomy and Open Surgery in Staghorn Stone Patients: Systematic Review
}

\author{
Ramandita Duta Dewangga $^{1(\mathrm{CA})}$, Tarmono Djojodimedjo ${ }^{2}$, Dyah Erawati $^{3}$ \\ ${ }^{1(\mathrm{CA})}$ Faculty of Medicine, Universitas Airlangga, Indonesia; ramanditaduta@ gmail.com (Corresponding Author) \\ ${ }^{2}$ Department of Urology, Faculty of Medicine, Universitas Airlangga / Soetomo General Hospital, Surabaya, \\ Indonesia \\ ${ }^{3}$ Department of Radiology, Faculty of Medicine, Universitas Airlangga / Soetomo General Hospital, Surabaya, \\ Indonesia
}

\begin{abstract}
This study purpose to analyze the differences in the effectiveness of PCNL and open surgery in patients with staghorn stones. We searched the literatures from PubMed and ScienceDirect from year 2005 until 2020. The method used in this study was a systematic review with a quantitative statistical approach (meta-analysis) using primary research data. From 4 studies there were 148 cases of PCNL and 98 cases of open surgery. PCNL had lower postoperative stone-free rate than open surgery (OR 0.168). PCNL had a lower final stone-free rate than open surgery (OR 0.603). The number of patients who had complications with PCNL was lower than open surgery (OR 0.451). The number of patients receiving blood transfusions on PCNL was lower than for open surgery (OR 0.494). Patients who received PCNL procedure required a shorter hospital stay than open surgery (MD -3,234). The number of patients who received additional therapy modalities on PCNL was lower than open surgery (OR 1.917). The conclusions obtained in this study indicate that there are differences in the effectiveness of PCNL and open surgery for patients with staghorn stones.
\end{abstract}

Keywords: percutaneous nephrolithotomy; open surgery; staghorn stone

\section{Background}

\section{INTRODUCTION}

Urinary tract stone disease is the formation of stones caused by the deposition of substances in the urine in excessive amounts or due to other factors that affect the solubility of substances. In the United States, among 11 people there is 1 person who has kidney stones, and an estimated 600,000 Americans develop urinary tract stones each year. In the Indian population, about $12 \%$ of the population is estimated to have urinary tract stones and $50 \%$ of them end in loss of kidney function. ${ }^{(1)}$ Indonesia shows that the prevalence of the Indonesian population suffering from kidney stones is $0.6 \%$ or 6 per 1000 population. In Dr. Soetomo in 2016, there were 62 urinary tract stone patients. ${ }^{(2)}$

There are several types of urinary tract stones from the many incidences of urinary tract stones, one of which is staghorn stones. ${ }^{(3)}$ Staghorn stones are branched kidney stones that fill part or all of the renal pelvis and kidney calices so that they resemble deer antlers. Due to the significant morbidity and mortality potential of staghorn stones, immediate assessment and treatment are needed. ${ }^{(4)}$

Several therapeutic modalities can be chosen, including PCNL or open surgery. Open surgery was once considered the "gold standard" for handling staghorn stones. However, thanks to advances in technology and science the handling of staghorn stones have been revolutionized. The American Urological Association (AUA) guidelines for the management of staghorn stones recommend PCNL as the modality of choice and standard of practice. But for several reasons, not a few urologists also recommend open surgery for patients with staghorn stones. ${ }^{(5)}$

\section{Purpose}

This study aimed to analyze the differences in the effectiveness of PCNL and open surgery so that it can be considered in the administration of therapy in patients with staghorn stones.

\section{METHODS}

The type of research used in this study was a systematic review using primary research results. This study used a meta-analysis approach, the selected primary research results were then synthesized using a statistical 
(quantitative) approach. Journal searches were performed on the PubMed and ScienceDirect databases. To simplify the search, the keywords "PCNL" or "open surgery" were used in combination with "staghorn stone patient". The selected period is the last 15 years, namely 2005 to 2020.

Assessment of journal quality was carried out using dual tools, namely the NOS (Newcastle Ottawa Scale) for the case-control method study and the CONSORT checklist for the RCT (Randomize Controlled Trial) method. The independent variable of this study was the PCNL, open surgery. Meanwhile, the dependent variable of this study was the stone-free rate, complications, blood transfusion, hospitalization, and additional therapy modalities.

\section{RESULTS}

There were 3002 studies were found from databese using keywords but, finally. There were 4 studies included in this study. Of the 4 selected studies, there were 246 cases, with 148 cases undergoing PCNL and 98 cases receiving open surgery.

Table 1. Studies characteristic

\begin{tabular}{ccccccc}
\hline Study & Study design & Time study & Operation & Average age & Case $(\mathrm{n})$ & Average stone size \\
\hline $\begin{array}{c}\text { Al-Kohlany KM et al } \\
2005\end{array}$ & \multirow{2}{*}{ RCT } & \multirow{2}{*}{$2001-2003$} & PCNL & $48.6 \pm 8.5$ & 43 & $18.7 \pm 6.9 \mathrm{~cm}^{3}$ \\
\cline { 4 - 6 } & & & Open surgery & $48.7 \pm 10.9$ & 45 & $18.8 \pm 8.1 \mathrm{~cm}^{3}$ \\
\hline $\begin{array}{c}\text { Aminsharifi A et al } \\
2016\end{array}$ & \multirow{2}{*}{ Case-control } & \multirow{2}{*}{$2010-2015$} & PCNL & $48 \pm 8.57$ & 16 & $79.06 \pm 15.63 \mathrm{~mm}$ \\
\cline { 4 - 6 } & & Open surgery & $48.21 \pm 7.87$ & 14 & $77.0 \pm 14.33 \mathrm{~mm}$ \\
\hline $\begin{array}{c}\text { El-Nahas AR et al } \\
\text { 2014 }\end{array}$ & \multirow{2}{*}{ Case-control } & \multirow{2}{*}{$2000-2013$} & PCNL & $7.1 \pm 2.93$ & 28 & \\
\cline { 4 - 6 } $\begin{array}{c}\text { Zhang FBY et al } \\
\text { 2017 }\end{array}$ & \multirow{2}{*}{ Case-control } & \multirow{2}{*}{$2007-2013$} & Open surgery & $7.6 \pm 3.31$ & 28 & \\
\cline { 3 - 6 } & & Open surgery & $50.5 \pm 11.1$ & 11 & $19.7 \pm 6.4 \mathrm{~cm}^{2}$ \\
\hline
\end{tabular}

\section{Free-rate Stone}

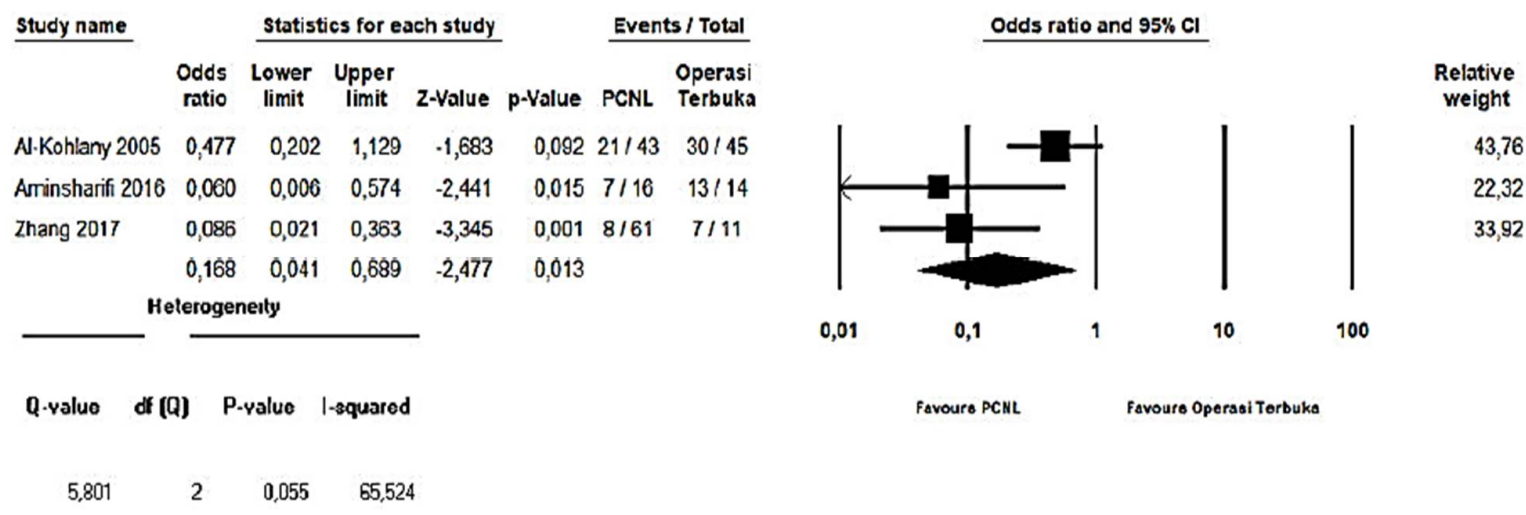

Figure 1. Forest plot of post treatment stone-free rate.

In the assessment of the stone-free number after the action, the randomized effect model was used. Of the 4 studies that have been selected, there is one study that does not have post-treatment stone-free number data, namely the study from El-Nahas. Meta-analysis and Forest Plot showed that PCNL had significantly smaller postprocedure stone-free results compared to open surgery, this difference was clear (OR 0.168; 95\% CI 0.041-0.689; $\mathrm{p}=0.013)$, with heterogeneity between significant study $(\mathrm{Q}=5.801 ; \mathrm{I} 2=65.524)$.

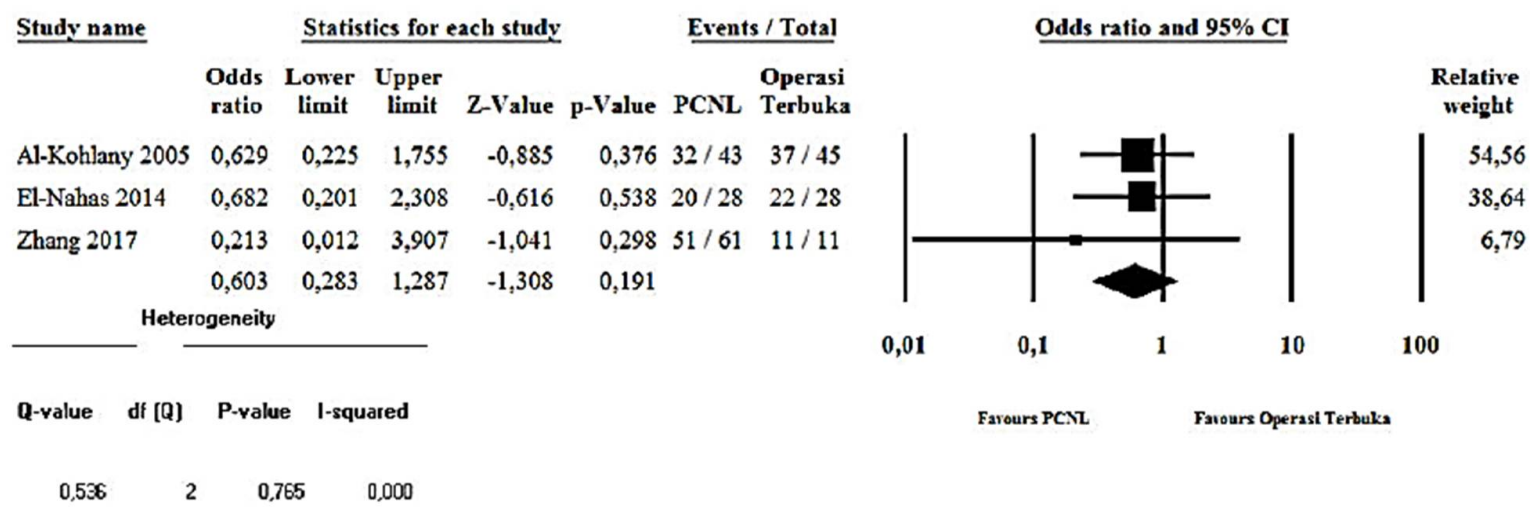

Figure 2. Forest plot of final stone-free rate 
The final stone-free rate examined in the study was the stone-free rate 3 months postoperatively, except for the study of Aminsharifi and colleagues (2016) which examined 12 months postoperatively. All four studies showed final stone-free rates, but in the Aminsharifi study, PCNL and open surgery had $100 \%$ results. The combined analysis of 3 studies showed that the final stone-free rate in the PCNL group was 78.03\% (103/132) and open surgery $83.33 \%$ (70/84). From the results of Figure 5.2 it can be seen that PCNL has a lower final stonefree rate than open surgery, although the difference is not so significant (OR 0.603; 95\% CI 0.283-1.287; p = $0.191)$. There was no statistical heterogeneity between studies, assessed by $(\mathrm{Q}=0.536 ; \mathrm{I} 2=0.000)$.

\section{Complications}

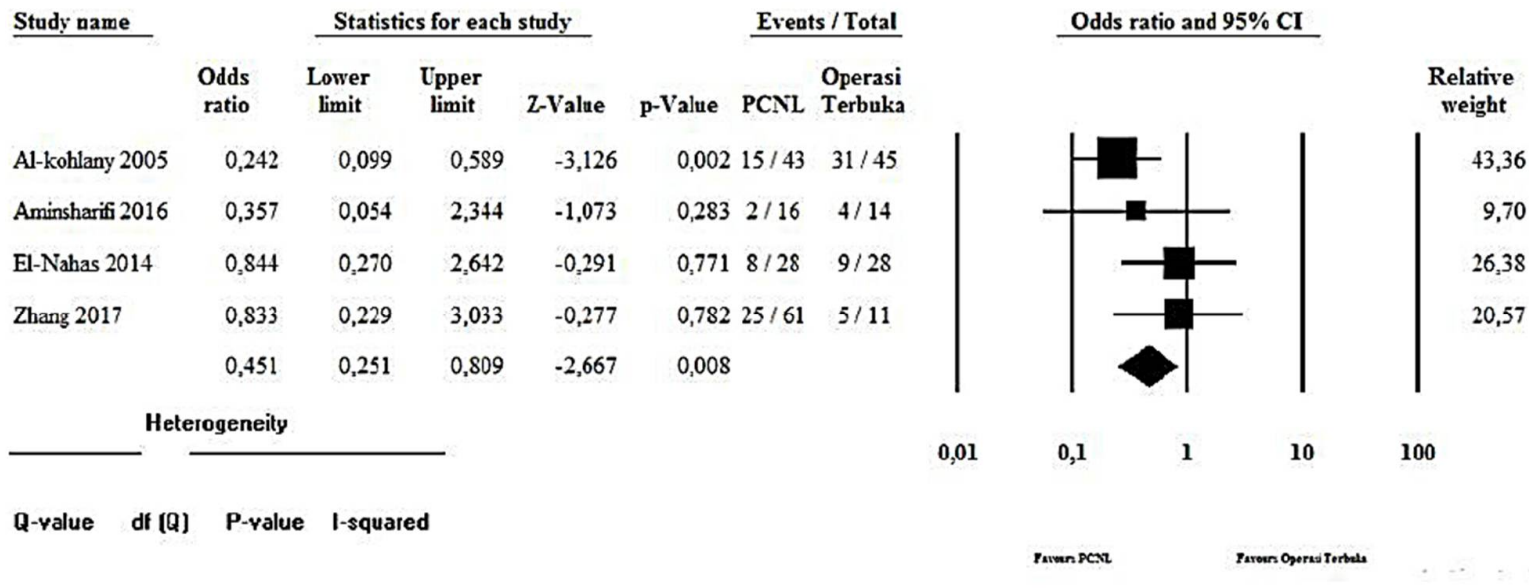

Figure 3. Forest plot of complications

The parameter assessed was the total number of complications. All four studies reported overall complications. It can be seen that the number of patients who have complications with PCNL is lower compared with open surgery (OR $0.451 ; 95 \%$ CI $0.251-0.809 ; \mathrm{p}=0.008)$, but with low heterogeneity between studies $(\mathrm{Q}=$ $3.970 ; \mathrm{I} 2=24.440)$.

\section{Blood Transfusion}

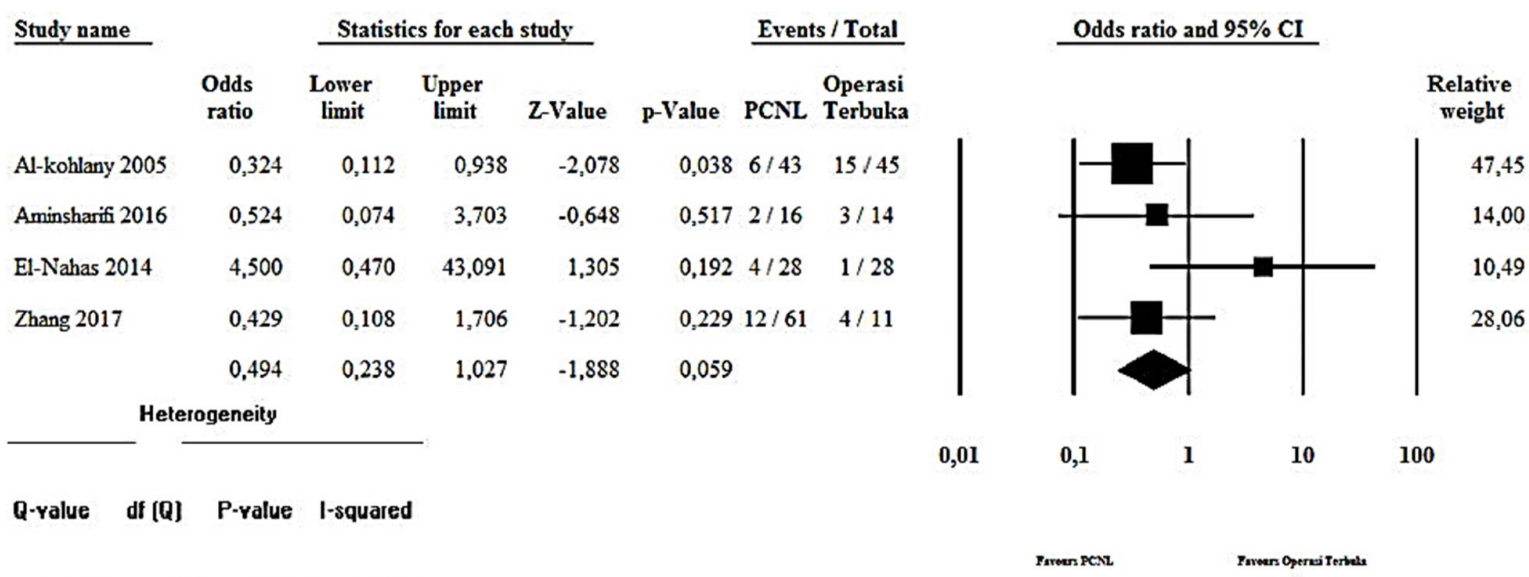

Figure 4. Forest plot of blood transfusion

Meta-analysis shows that the number of patients requiring blood transfusion on PCNL is lower compared with open surgery (OR $0.494 ; 95 \%$ CI $0.238-1.027$; $=0.059)$, with moderate heterogeneity between studies (Q $=4.320 ; \mathrm{I} 2=30.563)$.

\section{Length of Hospital Stay}

The random-effects model was used in the assessment of the length of stay. Length of stay was reported in all four studies. Patients who receive PCNL get a shorter length of stay if compared with patients who received open surgery (random-effects model; MD -3.234; 95\% CI -4.253 - -2.215; p = 0.000), with significant heterogeneity between studies $(\mathrm{Q}=6.390 ; \mathrm{I} 2=53.0 \%)$. 


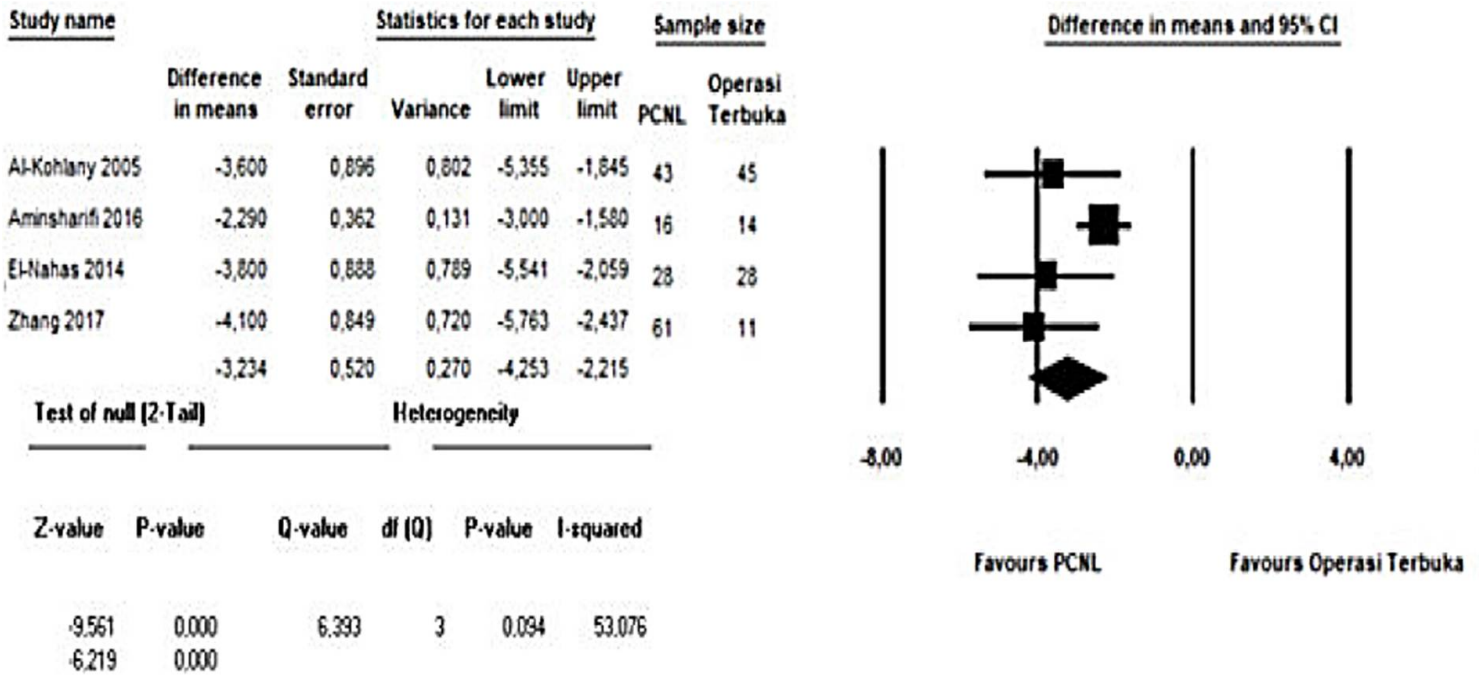

Figure 5. Forest plot of length of hospital stay

Additional Therapeutic Modalities

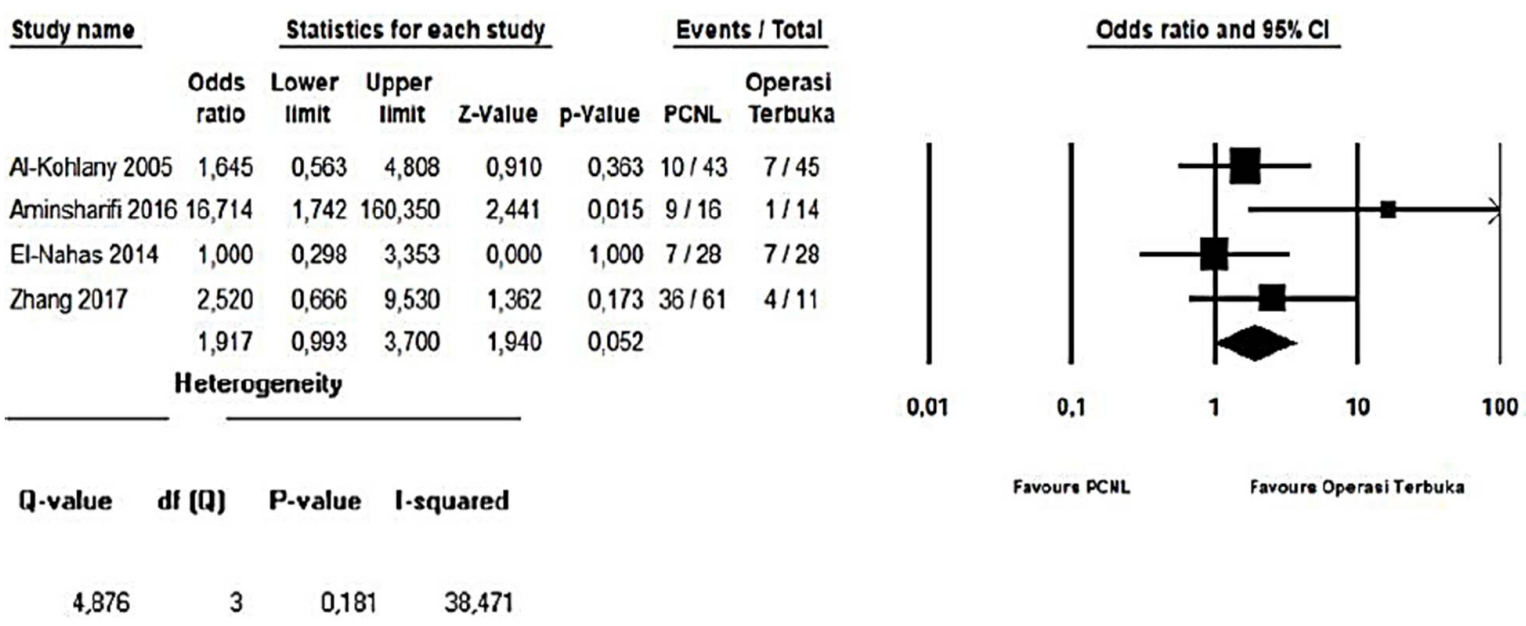

Figure 6. Forest plot of additional therapeutic modalities

In the additional modality assessment, enter data on the number of cases that receive additional modality for residual stones. The number of patients who received additional therapy modalities on PCNL was higher than open surgery (OR 1.917; 95\% CI 0.993-3.700; $\mathrm{P}=0.052)$, with moderate heterogeneity between studies $(\mathrm{Q}=4.876 ; \mathrm{I} 2=38.471)$.

\section{DISCUSSION}

In the observed stone-free rate is divided into post-treatment stone-free rate and final stone-free rate. The randomized effect model was used in the assessment of the stone-free number after the action because of the significant heterogeneity between studies. The results of the meta-analysis revealed that open surgery provided a significantly higher statistical post-treatment stone-free rate than PCNL. Stone free rate data after 3 months in the journal by Zhang et al. (2017) shows that the ratio of final stone-free rates in open surgery is higher than PCNL, with a ratio of $100 \%$ vs $84 \%$. Although the results of the combined assessment show that open surgery provides a statistically significant high postoperative stone-free rate compared to PCNL, no significant difference was found in the final stone-free rate. In fact, Aminsharifi and colleagues (2016) showed the final stone-free rate data on PCNL and open surgery which was $100 \%$ in both measures which made it unpredictable by the forest plot. ${ }^{(6,7)}$

Although the PCNL meta-analysis had a relatively lower stone-free rate compared to open surgery, this could be compensated for by the lower complications. The difference in complication rates is related to the magnitude of the invasive approach given to patients with staghorn stones. In open surgery, the action given is more invasive. In PCNL the procedure is minimally invasive. In PCNL, the operation is performed by making a 
small puncture about $1 \mathrm{~cm}$ in the waist area of the patient, although this cannot be separated from the complexity of the PCNL procedure, while open surgery can result in a wider open incision. ${ }^{(8)}$

In keeping with open surgery which is more invasive as it requires a wider incision compared to PCNL which only requires a relatively small puncture, open surgery makes the renal parenchyma more susceptible to injury. Therefore, it tends to result in various complications such as nephron damage and bleeding, leading to more frequent blood transfusions. The combined meta-analysis data showed that the number requiring blood transfusion on PCNL was less than open surgery (OR 0.494). Risk factors for severe bleeding are the means of achieving a superior calyx, solitary kidney, staghorn stones, number of punctures, and surgeon experience. In the study of El-Nahas et al. (2014) showed that PCNL has a higher number of patients requiring blood transfusions than open surgery (OR 4.5). One of the influencing factors is the younger age group. Moreover, the concerns about PCNL in children include the use of large instruments due to small kidney size, the risk of major complications, including sepsis and bleeding. ${ }^{(9-11)}$

The meta-analysis showed that patients who received PCNL had a shorter length of stay in the hospital than open surgery. In the analysis of length of stay, it has quite significant heterogeneity. There is even one study whose results are not cut off by the centerline of combined data (diamonds), namely the study from Aminsharifi (2016). The patient's age, Body Mass Index (BMI), stone size, and length of time of surgery did not affect the length of stay. ${ }^{(7),(12)}$

Aminsharifi (2016) showed the results of patients after receiving additional therapeutic modalities, had a stonefree rate on PCNL 9 primary action from 9 to be stone free. The meta-analysis showed that the PCNL procedure had more patients requiring additional therapeutic modalities than open surgery. This difference looks significant. However, data from El-Nahas and colleagues (2014), show a similarity in results between PCNL (Percutaneous Nephrolithotomy) and open surgery. Each study has its criteria for implementing additional therapy modalities. ${ }^{(7),(9)}$

\section{CONCLUSION}

The postoperative stone-free rate on PCNL (Percutaneous Nephrolithotomy) is lower when compared to open surgery, one of the contributing factors is because PCNL is a surgical procedure that requires high skills. However, it has a not too different final stone-free number. The number of patients who have complications in PCNL (Percutaneous Nephrolithotomy) is less than those with open surgery. The number of patients requiring blood transfusion on PCNL (Percutaneous Nephrolithotomy) is less than that of open surgery because open surgery is more invasive, it requires a wider incision than PCNL which only requires a relatively small puncture, open surgery makes the renal parenchyma more susceptible to injury. Therefore, it tends to cause bleeding, so blood transfusions are more common. Patients who receive PCNL (Percutaneous Nephrolithotomy) require a shorter hospital stay than open surgery. The number of patients who require additional therapy modalities on PCNL (Percutaneous Nephrolithotomy) is more when compared to open surgery.

\section{REFERENCES}

1. Alelign T, Petros B. Kidney Stone Disease: An Update on Current Concepts. Advances in Urology. 2018;1-12.

2. Kurniawan R, Djojodimedjo T, Rahaju S. Profile of Patients with Urinary Tract Stone at Urology Department of Soetomo General Hospital Surabaya in January 2016-December 2016. Indonesian Journal of Urology. 27(1).

3. Gellin C. Urinary Tract Stones. Pediatrics in Review. 2019;40(3):154-156.

4. Diri A, Diri B. Management of staghorn renal stones. Renal Failure. 2018;40(1):357-362.

5. Chen Y, Feng J, Duan H, Yue Y, Zhang C, Deng T, Zeng G. Percutaneous Nephrolithotomy versus open surgery for surgical treatment of patients with staghorn stones: A systematic review and meta-analysis. PLOS ONE. 2019;14(1).

6. Zhang FBY, Lin WR, Yang S, Hsu JM, Chang HK, Chen M, Chiu AW, Lin WC. Outcomes of percutaneous nephrolithotomy versus open stone surgery for patients with staghorn calculi. Urological Science. 2017;28(2):97-100. doi: 10.1016/j.urols.2017.02.001.

7. Aminsharifi A, Irani D, Masoumi M, Goshtasbi B, Aminsharifi A, Mohamadian R. The management of large staghorn renal stones by percutaneous versus laparoscopic versus open nephrolithotomy: a comparative analysis of clinical efficacy and functional outcome. Urolithiasis. 2016;44(6):551-557. doi: 10.1007/s00240-016-0877-6.

8. Sabler IM, Katafigiotis I, Gofrit ON, Duvdevani M. Present indications and techniques of percutaneous nephrolithotomy: What the future holds? Asian Journal of Urology. 2018;5(4):287-294. DOI: https://doi.org/10.1016/j.ajur.2018.08.004.

9. EL-Nahas AR, Shokeir AA, Shoma AM, Eraky I, Sarhan OM, Hafez AT, Dawaba MS, Elshal AA, Ghali AM, EL-Kenawy MR. Percutaneous nephrolithotomy versus open surgery for treatment of staghorn stones in pediatric patients. Canadian Urological Association Journal. 2014;8(906):11-12. DOI:10.5489/cuaj.1994.

10. Syahputra FA, Birowo P, Rasyid N, Matondang FA, Noviandrini E, Huseini MH. Blood loss predictive factors and transfusion practice during percutaneous nephrolithotomy of kidney stones: a prospective study. F1000Research. 2016;5:1550. DOI: https://doi.org/10.12688/f1000research.8993.1.

11. Desai M. Endoscopic management of stones in children. Current Opinion in Urology. 2005;15(2):107-112. DOI: https://doi.org/10.1097/01.mou.0000160625.59107.fd.

12. Alyami F, Norman RW. Is an overnoght stay after percutaneous nephrolithotomy safe?. Arab Journal of Urology. 2012;10(4):367-371. https://doi.org/10.1016/j.aju.2012.07.006. 